Integrating Cognitive-Behavioral and Cognitive-Interpersonal Case Formulations:

A Case Study of a Chinese American Male

E.T. Liu

Pragmatic Case Studies in Psychotherapy, http://pcsp.libraries.rutgers.edu

Volume 3, Module 3, Article 1, pp. 1-33, 07-27-07 [copyright by author]

EDITOR'S NOTE FOR VOLUME 3, MODULE 3: This module is organized around the case of a Chinese American therapist, Emily Liu, who conducted treatment with a Chinese American client ("TC") in the context of Liu's doctoral psychology training program. The Commentaries are distinctive in focusing on three major issues.

First, the initial two Commentaries (articles 2 and 3) are by Brian Chu and Wei-Chin Hwang, national experts on the types of cross cultural issues raised by the case. They focus on clinically adapting European-developed therapy models to the needs of Asian American clients.

Second, the next two Commentaries, by faculty in Liu's training program, illustrate the give-and-take relationship between developing systematic, therapy case studies and clinical training. Specifically, article 4 by Masha Mednikov, the clinical supervisor of the case, describes the process of helping Liu contend with the complexities of the client-therapist relationship, particularly TC's initial, intensely off-putting interpersonal behaviors. Then article 5 by Pauline Lytle, a professor who taught Liu in a generic clinical skills course, discusses how Liu's case and case study was employed as a particular context for skills development.

Third, this group of articles is multitheoretical in nature. Liu's case itself integrates cognitive-behavioral and cognitive-interpersonal models; the Commentaries by Chu and by Hwang \& Wood both employ a primarily cognitive-behavioral perspective; Mednikov's Commentary employs a primarily psychodynamic perspective; and Lytle's, a primarily family systems perspective. I am impressed by the ways in which all the authors balance their theoretical commitments with the clinical realities and demands of TC's case, achieving a complementarity among the different theoretical perspectives in the article series.

\title{
Integrating Cognitive-Behavioral and Cognitive-Interpersonal Case Formulations: A Case Study of a Chinese American Male
}

\section{EMILY TUNG-HSUEH LIU}

\author{
College of Medicine, Fu-Jen University, Taiwan
}

\footnotetext{
${ }^{a}$ Department of Clinical Psychology, College of Medicine, Fu-Jen University, Taiwan

${ }^{\mathrm{b}}$ Correspondence concerning this article should be addressed to Emily Tung-Hsueh Liu, Dept. of Clinical Psychology, College of Medicine, Fu-Jen University, 510 Chung Cheng Rd , Hsinchuang, Taipei County 24205, Taiwan

Email: emilythliu@gmail.com

Notes: This manuscript is an expanded and modified version of a poster presented at the First Asian CBT Conference (Chinese University of Hong Kong, May 28-30, 2006).

The author is a graduate of the California School of Professional Psychology -- San Francisco Bay Campus.
}

\section{ABSTRACT}

This case study presents "TC," a mid-20s Chinese American male with Major Depressive Disorder and Generalized Anxiety Disorder, whom I saw in therapy for 41 sessions. Case formulation and treatment were based on an integration of three approaches: Beck and his group's Cognitive Therapy; Persons and Tompkins' Cognitive-Behavioral Case Formulation 
Integrating Cognitive-Behavioral and Cognitive-Interpersonal Case Formulations:

A Case Study of a Chinese American Male

E.T. Liu

Pragmatic Case Studies in Psychotherapy, http://pcsp.libraries.rutgers.edu

Volume 3, Module 3, Article 1, pp. 1-33, 07-27-07 [copyright by author]

model; and Safran and Segal's model of Cognitive-Interpersonal Cycle. Specific interventions such as "cognitive restructuring" and "metacommunication" were implemented. The case is notable for its emphasis on the value of examining and constructively using a cognitive therapist's personal reactions to a client's dramatically negative interpersonal behaviors, and on the importance of using the here-and-now in the exploration and modification of the client's cognitions and behaviors. Further, it suggests the possibility of a culture-specific challenge in doing cognitive-behavioral therapy (CBT) with clients of Chinese origin. Specifically, the case shows how certain thoughts that were drawn from cultural values of achievement and humility (e.g., "Keep telling yourself that you are not good enough," and "Don't ever be satisfied with your accomplishments") may have contributed to this client's depression and anxiety, while at the same time these thoughts also seemed to motivate this self-disciplined individual to become a more successful person. Specific clinical implications are discussed.

Keywords: cognitive therapy; cognitive-behavioral therapy (CBT); cognitive-interpersonal therapy; caseformulation; Chinese cultural values; Chinese American clients

\section{CASE CONTEXT AND METHOD}

\section{A. The Rationale for Selecting This Particular Client for Study}

"TC," a mid-20s, 1.5 generation Chinese American male at a U.S. graduate school, initially presented with depression, anxiety, and anger. TC's case is distinctive for at least three reasons. First, he was a challenging client with dramatically negative interpersonal behaviors, such as (eye-rolling, sneering, sarcasm, and avoidance of eye contact). Given the striking impact of TC's unique characteristics and behaviors upon the feelings of other people, Safran and Segal's (1990) theory of "cognitive-interpersonal cycle" was integrated with classical cognitive therapy approaches (Beck, 1964; 1979; Persons \& Tompkins, 1997) as the guiding conception for the case. Second, the case report highlights the value of examining and utilizing the cognitive therapist's personal reactions to the client, which facilitate the application of "metacommunication" strategies, i.e. interventions involving explicit communication about therapist-client interactions. Lastly, the case report suggests a culture-specific challenge in doing CBT with Chinese clients such that certain self-defeating beliefs (e.g., "I am not good enough") were difficult to challenge, because the client may believe they also serve positive, motivating functions. These beliefs may stem from deeper cultural values, such as the emphases on achievement and humility.

\section{B. The Methodological Strategies Employed for Enhancing the Rigor of the Study}

TC was treated during my doctoral training. I received weekly individual supervision, and discussed the case in a biweekly group supervision at the agency. In addition, I presented the case and consulted with a professor and fellow doctoral students in a group that met weekly during the school year. The supervision groups provided me with a safe atmosphere in which I 
Integrating Cognitive-Behavioral and Cognitive-Interpersonal Case Formulations:

A Case Study of a Chinese American Male

E.T. Liu

Pragmatic Case Studies in Psychotherapy, http://pcsp.libraries.rutgers.edu

Volume 3, Module 3, Article 1, pp. 1-33, 07-27-07 [copyright by author]

could openly explore my concerns and become aware of potential blind spots. The intensive monitoring of the case facilitated by the individual supervision and supervisory groups was very helpful in focusing me on the progress that the client made. In addition, two standardized, selfreport instruments were administered in the beginning, middle, and final phases of the therapy: the Burns Anxiety Inventory (Burns, 1989) and the Burns Depression Checklist (Burns, 1989).

\section{The Clinical Setting in Which the Case Took Place}

TC was referred to a nonprofit community mental health clinic by a physician who had been treating his injured knee. The clinic was funded by the county, and clients who met certain criteria (e.g., residing in the area, low-income) received psychotherapy at no charge.

\section{Sources of Data Available Concerning the Client}

I was TC's second therapist. Born in Taiwan, I began studying in the U.S. when I was 14, and had been in the U.S. for 11 years by the time I saw TC. Prior to the treatment with me, TC had seen a 26-year-old Chinese American male cognitive therapist for 8 months, and therapy was interrupted for approximately 2 months due to the end of the therapist's internship with the agency. I obtained TC's permission for me to communicate with his previous therapist, Mr. S., by phone. Based on the phone conversation, progress notes, and termination summary, the previous therapist often felt that there was nothing he could do to help TC, and remarked that his own personal feelings of helplessness in working with TC seemed parallel to TC's general feelings of helplessness. In working with TC, Mr. S. initially focused on helping TC with his anger and depression by direct disputational dialogue. As TC's response to this confrontational approach was unfavorable, the therapist subsequently modified his approach by engaging in less dialogue and allowing more room for TC to process his thoughts and feelings. As a result, the relationship between TC and the therapist seemed to improve. However, Mr. S. stated that TC's presenting concerns remained mostly unresolved.

\section{E) Confidentiality}

To ensure confidentiality, the client's name and identifying information have been changed, although the "clinical reality" of this case has been retained. However, as TC's current contact information is not available, I am, unfortunately, unable to contact him concerning follow-up assessment.

\section{THE CLIENT}

At intake TC was a 26-year-old, never-married Chinese American male residing with his 57-year-old mother in a rental apartment in a large metropolitan area in the U.S. He was a second-year graduate student in the technical-scientific field at a university. Born in China, TC and his family immigrated to the U.S. when he was 11 years old. He spoke his native language, Cantonese, at home. Though with a moderate Cantonese accent, TC spoke English fluently. TC was of average height and slightly heavier than average. With a pair of old-fashioned glasses, TC 
Integrating Cognitive-Behavioral and Cognitive-Interpersonal Case Formulations:

A Case Study of a Chinese American Male

E.T. Liu

Pragmatic Case Studies in Psychotherapy, http://pcsp.libraries.rutgers.edu

Volume 3, Module 3, Article 1, pp. 1-33, 07-27-07 [copyright by author]

came to therapy mostly wearing a sweater, a pair of ankle-length slacks, and shoes without socks. Due to a knee injury, TC tended to walk slowly, though he did not limp. Immediately striking about TC was his dramatically negative interpersonal behaviors, such as eye-rolling, sneering, sarcasm, and avoidance of eye contact.

In the beginning of the treatment with me, TC reported symptoms of depression (e.g., hopelessness, poor self-image, suicidal ideation, sleep problems); anxiety (e.g., worries, difficulty concentrating); and anger related to school, family issues, and his knee injury.

\section{GUIDING CONCEPTION WITH RESEARCH AND CLINICAL EXPERIENCE SUPPORT}

Three therapeutic models were employed in TC's case. These included Cognitive Therapy as developed and refined by Beck and his group (e.g., A. Beck, 1964; A. Beck, Rush, Shaw, \& Emery, 1979), and the related Cognitive-Behavioral Case Formulation model as proposed by Persons and Tompkins (1997). In addition, given that TC presented with the dramatically negative interactional behaviors referred to earlier (e.g., eye-rolling, sneering, sarcasm, and avoidance of eye contact) that would tend to generate strong negative reactions in others, the Cognitive-Interpersonal Cycle model of Safran \& Segal (1990) was also employed. Features and relevant findings of each model will be discussed below.

\section{Cognitive Therapy}

Numerous studies have found cognitive therapy to be effective for treating depression and anxiety (Barlow, Craske, Cerney, \& Klosko, 1989; Butler, Fennell, Robson, \& Gelder, 1991; Dobson, 1989; Giles, 1993). Consistent with what the ancient philosopher Epictetus (100 A.D.) is purposed to say, "What disturbs people's minds is not events but their judgments on events," cognitive therapists maintain that how an individual construes external events determines how he/she feels (Beck, 1964; Ellis, 1962). Schemas are defined as cognitive structures within the mind, and the specific contents of the cognitive structure are called core beliefs (Beck, 1976). Core beliefs are the most fundamental level of cognition, and often present as absolutistic statements about the self, others, and the world (Beck, 1976). Cognitive therapy emphasizes clients' active participation, teaching clients to identify, evaluate, and respond to their own thoughts and beliefs (Beck, J., 1995). Further, cognitive therapy employs a variety of techniques to change clients' cognition, emotion, and behavior (Beck, J., 1995).

\section{Cognitive-Behavioral Case Formulation}

Drawing upon A. Beck's (1976) cognitive theory of emotional disorders, Persons and Tompkins (1997) developed the Cognitive-Behavioral Case Formulation model. The goal was to provide clinicians with a strategy for developing individualized, comprehensive, theory-based treatment plans for their clients (Persons \& Tompkins, 1997). The eight components of the case 
Integrating Cognitive-Behavioral and Cognitive-Interpersonal Case Formulations:

A Case Study of a Chinese American Male

E.T. Liu

Pragmatic Case Studies in Psychotherapy, http://pcsp.libraries.rutgers.edu

Volume 3, Module 3, Article 1, pp. 1-33, 07-27-07 [copyright by author]

formulation model are closely linked to Beck's theory and include: 1) identifying information; 2) problem list; 3) core beliefs; 4) precipitants and activating situations; 5) working hypothesis; 6) origins; 7) treatment plan; and 8) predicted obstacles to treatment. The Persons and Tompkins model was applied directly to TC's individual case formulation, as described in section 5 below.

\section{Cognitive-Interpersonal Cycle}

Traditional cognitive therapy emphasizes that psychopathology is associated with overly rigid, negatively distorted beliefs per se, and because of this it has been criticized for its lack of emphasis on interpersonal factors (Safran \& Segal, 1990). It is quite possible that some depressed individuals do not show distortion in their perceptions, but in fact, their interpersonal context may be extremely negative and unpleasant, and they play significant roles in it (Safran \& Segal, 1990). Coyne (1976) reported that in interpersonal situations, depressed individuals often demonstrate a unique interpersonal style -- focusing primarily on themselves and speaking in negative tones with the goal of communicating self-devaluation, sadness, and helplessness. In addition, following interactions with the depressed individuals, family members often find themselves experiencing more negative feelings, such as anger and hostility (Coyne, 1976). The cognitive-interpersonal cycle often creates a vicious circle: An individual who believes that others are untrustworthy may distance others further by behaving in a suspicious manner, thereby confirming his original belief that nobody likes him and that nobody should be trusted.

Instead of viewing the cognitive and interpersonal approaches as separable, the cognitiveinterpersonal approach attempts to integrate the two. The fundamental notion of the cognitiveinterpersonal approach is that the individuals both construe and construct their environments; accordingly, clients must always be viewed as part of the interpersonal system in which they are is participating (Safran \& Segal, 1990). The client's presenting concerns may reflect the reality of his or her interpersonal world, and the therapist - by being a part of the therapeutic relationship - is able to explore and deal with the cognitive processes that are associated with the client's interpersonal cycle in the here-and-now (Safran \& Segal, 1990).

\section{ASSESSMENT OF THE CLIENT'S PROBLEMS, GOALS, STRENGTHS, AND HISTORY}

\section{History}

TC was the youngest of three siblings, and his birth followed an unplanned and unwanted pregnancy. TC's parents seriously considered abortion, but eventually decided to continue with the pregnancy. When TC was 11 years old, his family immigrated to the United States for economic and educational opportunities. As recent immigrants, however, TC's parents faced multiple stressors (e.g., limited English skills; lack of social/informational support; and lack of familiarity with the social/legal systems in the U.S.), and they sadly realized that it was difficult to make a living in the large metropolitan area in which they were located. The financial hardship and other stressors led to marital conflicts between his parents. At the age of 12 years, 
Integrating Cognitive-Behavioral and Cognitive-Interpersonal Case Formulations:

A Case Study of a Chinese American Male

E.T. Liu

Pragmatic Case Studies in Psychotherapy, http://pcsp.libraries.rutgers.edu

Volume 3, Module 3, Article 1, pp. 1-33, 07-27-07 [copyright by author]

TC became aware of the tumultuous relationship between his parents. TC's mother often complained that TC's father did not try hard enough to find a job. Five years following the immigration, TC's parents bought a grocery. At the same time, TC's father began gambling extensively.

TC's mother had a habit of hoarding items (e.g., used containers) in the apartment. Though TC understood her idea of holding on to things that might someday be useful, the apartment eventually became so cluttered that TC felt the need to throw away much of the collection. As soon as TC did so, his mother retrieved it from the garbage. TC reported that he had even taken pictures of his apartment and shared them with others to demonstrate the extent of the mess.

TC's two older sisters had been very successful in high school. Both then graduated from prestigious universities. His 33-year-old sister married a wealthy man, and his 28-year-old sister worked as a dentist. TC graduated from a public high school, where he had average grades. His first depressive episode occurred during his senior year in high school, upon learning that he was not accepted to any of the colleges of choice. He attended a community college for two years, subsequently transferred to a state university, and obtained a B.S. in an engineering-related major 4 years later.

Family conflicts intensified during TC's college years. His father lost a great deal of money gambling, and as a result, the family was forced to sell the grocery. Since then, TC's mother had been working for the new owner of the business. His parents divorced when TC was 19. TC maintained contacts with his father. Six months after graduation from college, TC found his first job doing administrative work at a company. Excitedly, he took driving lessons, obtained a driver's license, bought a car, and started his job. After 5 months, however, he quit as he felt that his coworkers did not like him and that they looked down on him. TC reported having a few "so-called 'friends,"' but he emphasized that none of them was a close or good friend. Selfreported as heterosexual, he had never had a girlfriend.

TC experienced his home environment as particularly stressful because he was the only child who did not contribute financially to the family, a major family value - although he did work hard in other ways to help in the family. TC described his relationship with his mother as emotionally distant with constant criticisms by her regarding his appearance and behaviors. For instance, his mother sometimes yelled at him, "Your fingernails are too long!," and at other times, "Your fingernails are too short!" His oldest sister used to be critically targeted occasionally, but as soon as her association with a wealthy man was secured, TC's mother had been treating her with much respect. TC avoided interactions with his nay-saying mother by not having meals at home and turning off the bedroom light and pretending that he was asleep as soon as he heard his mother's footsteps.

Fifteen months prior to the onset of the treatment with me, TC hit his knee against a metal pole while riding a bus, which resulted in a knee injury. Holding a firm belief that people 
Integrating Cognitive-Behavioral and Cognitive-Interpersonal Case Formulations:

A Case Study of a Chinese American Male

E.T. Liu

Pragmatic Case Studies in Psychotherapy, http://pcsp.libraries.rutgers.edu

Volume 3, Module 3, Article 1, pp. 1-33, 07-27-07 [copyright by author]

judge others based on outward appearance, especially on the way people dress, he attributed the cause of the accident to his "cheap clothes" and the bus driver's "intentionally hitting the gas when [he] got on the bus." After the accident, TC received physical therapy and walked with a cane for 5 months.

At intake, TC reported a history of suicidal ideation. Though no plans or attempts had been made, he clearly exhibited a death wish, and stated plainly that he would choose to kill himself if he could find a "fast, secure, and reliable" method. No such method had been found; the closest he came to acting on his suicidal ideation was when he thought about asking a "socalled "friend"' if he had a gun. Following Motto (1989)'s suggestions, the assessment of suicide risk involved asking direct questions in an empathic manner (e.g., the past and present experiences of feeling low or despondent; the intensity of suicidal ideation; the details of the suicide plans; the support system...etc.) Given TC's strong suicidal ideation, prevention of suicide was established as a treatment goal. Please note that the specific intervention will be discussed in subsequent sections. As mentioned above, also at intake TC reported symptoms of depression (e.g., hopelessness, poor self-image, suicidal ideation, and sleep problems); anxiety (e.g., worries and difficulty concentrating); and anger related to school, family issues, and his knee injury. When asked about his goals for therapy, TC stated that he would like to be happier in general.

\section{Psychometric Results}

The Burns Anxiety Inventory and the Burns Depression Checklist (Burns, 1989) were used as assessment tools, and were administered to TC in the beginning, middle, and final phases of therapy. The Burns Anxiety Inventory contains a list of 33 common symptoms of anxiety. The Burns Depression Checklist includes 15 symptoms of depression. TC was asked to check off how much each symptom bothered him in the past week. Each symptom is scored 0 for "not at all," 1 for "somewhat," 2 for "moderately," and 3 for "a lot." I decided to employ these scales because they were easy to use, psychometrically sound, and contained no jargon or confusing words. The means of TC's anxiety and depression scores, as reported in the different phases of therapy, are presented in Table 1. As can be seen, in the evaluation stage, TC obtained a 31 (in the severe range) on the depression scale, and a 30 (moderate range) on the anxiety scale.

TC was also asked to evaluate the quality of his sleep using a 10-point-scale. I asked him, "On a scale of 0 to 10 , with 0 being very poor, and 10 being very good, how would you rate the quality of your sleep in the past week?" The means of TC's sleep ratings, as reported in different phases of therapy, are shown in Table 2. As can also be seen, at the beginning of therapy, TC's rating of his sleep quality was 3 , in the poor range. 
Integrating Cognitive-Behavioral and Cognitive-Interpersonal Case Formulations:

A Case Study of a Chinese American Male

E.T. Liu

Pragmatic Case Studies in Psychotherapy, http://pcsp.libraries.rutgers.edu

Volume 3, Module 3, Article 1, pp. 1-33, 07-27-07 [copyright by author]

\section{Diagnoses and Strengths}

TC's DSM-IV (American Psychiatric Association, 1994) diagnoses were as follows:

Axis I $296.32 \quad$ Major Depressive Disorder, Recurrent, Moderate

300.02 Generalized Anxiety Disorder (rule out Social Phobia)

Axis II V71.09 No diagnosis, avoidant personality traits

Axis III Knee injury

Axis IV Problems with primary support group

Axis V $\quad$ GAF $=48$ (lowest of the year)

As indicated, TC met the criteria for the Axis I diagnoses of Major Depressive Disorder and Generalized Anxiety Disorder. In the clinical interview, TC reported the following depressive symptoms: Depressed mood most of the day; markedly diminished interest in almost all activities most of the day; insomnia; loss of energy; feelings of worthlessness; diminished ability to concentrate; and recurrent suicidal ideation without a specific plan. He also reported symptoms that were diagnostic of GAD: Excessive anxiety and worry; difficulties with controlling the worry; the anxiety and worry are associated with being easily fatigued; difficulty concentrating and mind going blank; muscle tension; and sleep disturbance. Further, although TC maintained his routine and his student status, both the depressive and anxiety symptoms had caused clinically significant distress in social, familial, and educational aspects of functioning. Social Phobia was placed in the "rule out" category because while TC did have the fears of embarrassment and humiliation in social situations that are central to Social Phobia, this was not the main focus of his fear and anxiety. Given his eye-rolling, sneering, sarcasm, and avoidance of eye contact, Tourette's Disorder may also be considered. However, it was ruled out because no vocal tics were observed; also, the motor movements were found to be related to anxiety.

On Axis II, TC did show signs of Avoidant Personality Disorder. However, the DSM-IV points out that avoidant behavior may be the result of problems in acculturation following immigration. I judged that this was the situation with TC and therefore did not assign him a diagnosis of Avoidant Personality Disorder.

TC's most notable strengths included diligence, resiliency, and honesty. He had worked very hard since he was a little child, and I was amazed by his ability to persevere. Further, although being angry at others and the world, he maintained his integrity and honesty. 
Integrating Cognitive-Behavioral and Cognitive-Interpersonal Case Formulations:

A Case Study of a Chinese American Male

E.T. Liu

Pragmatic Case Studies in Psychotherapy, http://pcsp.libraries.rutgers.edu

Volume 3, Module 3, Article 1, pp. 1-33, 07-27-07 [copyright by author]

\section{FORMULATION AND TREATMENT PLAN}

The case formulation of TC was developed by explicitly employing two of the approaches described above in section 3: Persons and Tompkin's (1997) CBT model, and Safran and Segal's (1990) cognitive-interpersonal cycle model.

\section{Cognitive Behavioral Case Formulation}

\section{$\underline{1 .}$ Identifying Information}

TC, a Chinese American male in his mid-20s, presented with depression, anxiety, and anger. He was referred to treatment following a knee injury.

\section{Problem List}

A. Recurrent suicidal ideation.

B. Trouble falling and staying asleep.

C. Feelings of worthlessness, accompanied by such thoughts as: "I am not good enough," "I don't have nice clothes," "People don't like me because of the way I look," "No one respects me," and "No one cares about me."

D. Feelings of hopelessness, accompanied by such thoughts as, "Nothing I do will ever be good enough," and "I don't think my life will ever get better."

E. Difficulties in studying, concentrating, and retrieving information effectively, accompanied by such thoughts as, "What's wrong with me?" and "I must be getting dumber."

F. Anger, accompanied by such thoughts as, "Others are treating me unfairly," "Why do my mother and my sisters make unfair interpretations of my situation?," and "No matter what happens, they always blame me."

G. Anxiety - worries, uncertainty about career choice; seeing himself as unable to cope; accompanied by such thoughts as, "What if I won't be able to graduate in two years?," and "What if I will end up being a failure - like my dad?"

H. Social Isolation - no close friends or girlfriend, accompanied by such thoughts as, "Of course they don't want to be around me; I am unattractive, stupid, and poor." 
Integrating Cognitive-Behavioral and Cognitive-Interpersonal Case Formulations:

A Case Study of a Chinese American Male

E.T. Liu

Pragmatic Case Studies in Psychotherapy, http://pcsp.libraries.rutgers.edu

Volume 3, Module 3, Article 1, pp. 1-33, 07-27-07 [copyright by author]

\section{Core Beliefs}

A. View of self: "I am worthless and unlovable."

B. View of others: "Others are better than me and do not accept me."

C. View of the world: "The world is a harsh and unfair place."

\section{Conditional Beliefs}

"If I am not perfect, then I will be ignored or rejected. If I impress people, they will like me. But if they get to know me, they'll think I am a loser."

\section{Origins}

TC reported that he was the result of an unplanned and undesirable pregnancy, and he seemed to be the least "successful" child in the family. The unexpected financial hardship and ensuing marital conflicts that the family experienced in the U.S. may have heightened the importance of financial security for TC's mother, who endured shame by working for the new owner of the grocery. As mentioned above, TC experienced his home environment as particularly stressful because he was the only child who did not contribute financially to the family. Also, among the three children, the overall stresses of moving to the U.S. probably hit TC the hardest because he was the youngest and thus moved at an earlier age in his development.

Moreover, the high standard that the Chinese culture places on educational accomplishment should be considered (Chen \& Davenport, 2005, Stevenson \& Lee, 1996). For many, "education" appears to be the only route through which Chinese individuals can achieve higher socio-economic status in American society (Louie, 2000). For example, TC often commented, "Having a B.A. is nothing. That degree can only help you stay out of working at McDonald's. Everyone has a bachelor's degree." "Family recognition through achievement" has been reported to be an important cultural value embraced by individuals of Chinese origins (Kim, Yang, Atkinson, Wolfe, and Hong, 2001). It refers to achieving academically to make one's parents proud and avoiding educational/occupational failure, so that one's family would not be shamed (Kim, Atkinson, and Yang, 1999; Kim et al., 2001). As cruel as it may sound, those who attain higher achievement are usually given more value and recognition, while those who achieve less are valued less by the family (K. Lin, 2003).

Witnessing his mother's differential treatment toward his sisters and himself, and receiving the overt and covert messages that he was the only child who had not yet demonstrated academic triumph or financial success, TC experienced a tremendous amount of pressure. Aside from comparing unfavorably to both older sisters, TC did not seem to fare well in the competition with the children of his mother's friends and acquaintances either. TC's taking 6 years to finish college seems to have led TC's mother and TC to feel that he was "below 
Integrating Cognitive-Behavioral and Cognitive-Interpersonal Case Formulations:

A Case Study of a Chinese American Male

E.T. Liu

Pragmatic Case Studies in Psychotherapy, http://pcsp.libraries.rutgers.edu

Volume 3, Module 3, Article 1, pp. 1-33, 07-27-07 [copyright by author]

average" in the Chinese community. Moreover, his tuition and expenses for the additional years entailed not only "a loss of face" for his family, but also added further financial strain on them.

Another cultural issue should be noted. TC's father's gambling problems and his parents' divorce may be sources of shame for TC. In traditional Chinese culture, a father serves as both the breadwinner and the role model in the family (K. Lin, 2003). Thus, the socio-economic status that TC's family occupies, and the traditional Chinese values on education and success, are likely to play significant roles in producing and reinforcing his self-defeating core beliefs.

\section{$\underline{\text { 6. Precipitants and Activating Situations }}$}

TC first became extremely depressed after being rejected by his college of choice, and again after injuring his knee on the bus (precipitants). Presently, he is likely to become distressed any time he receives negative feedback, e.g., getting a bad grade, or being disregarded or rejected in social and familial settings (activating situations).

\section{Working Hypothesis}

TC's maladaptive beliefs seem to play an important role in producing and perpetuating his depressive and suicidal feelings. TC's core beliefs -- "I am worthless," "Others are better than me," and "The world is unfair" - cause him to feel depressed, anxious, and angry whenever he is given negative feedback, or when he feels unsupported and isolated. Because of the negative emotions and thoughts that he constantly experiences, he is not able to do his schoolwork effectively, or to function in a spontaneous and socially desirable manner in social settings. As a result, he does not function optimally in school and ends up not having any close friends. Such "evidence" then reinforces his belief, "I am worthless and unlovable." The behavioral consequence is that he becomes even less effective at work, love, and play. The vicious cycle continues.

\section{$\underline{\text { 8. Predicted Obstacles to Treatment }}$}

The vicious cycle in TC's interpersonal behavior just mentioned seemed likely to be a problem in TC's developing a positive therapeutic relationship with me. Specifically, I assumed that TC's expectations of rejection from others and his "hair trigger" reaction of angry and/or withdrawing behaviors to any perceived negative feedback would be an obstacle to developing an open, give-and-take relationship with his therapist.

\section{Cognitive-Interpersonal Cycle Formulation}

In his initial interview, TC manifested dramatically negative interpersonal behaviors, such as eye-rolling, sneering, sarcasm, and avoidance of eye contact. I viewed these problematic in-session behaviors as a sample of the problem behaviors that brought TC into therapy in the first place. His depression signaled the presence of a generally dysfunctional interpersonal 
Integrating Cognitive-Behavioral and Cognitive-Interpersonal Case Formulations:

A Case Study of a Chinese American Male

E.T. Liu

Pragmatic Case Studies in Psychotherapy, http://pcsp.libraries.rutgers.edu

Volume 3, Module 3, Article 1, pp. 1-33, 07-27-07 [copyright by author]

context. In fact, TC's negative cognitions were likely to be reflective of interpersonal realities: Other people might in fact find him to be unpleasant and not accept him. Having learned that feeling angry would likely lead to rejection, TC had difficulty experiencing and expressing anger directly. The classic irony in TC's maladaptive, cognitive-interpersonal cycle is that it was perpetuated and maintained by his own attempt to deal with the problem (Safran \& Segal, 1990).

Thus, expecting others to be hostile, TC would end up eliciting hostility by his attempt to deal with the expected hostility. The nonverbal level of communication seemed to further complicate the situation. TC consistently interacted with people with a cynical look and a sneer, which led others to react with annoyance and irritation. These negative feelings leaked through into their interaction with TC, and contributed to TC's feeling even more resentful. Thus TC showed more resentment in his communication, which others, then, interpreted as extremely alienating and aggravating.

TC seemed to believe that if he let people see his anger they would reject him, and that if they saw his pain and vulnerability, they would be repulsed. Therefore, TC hid his true feelings. His cynicism and sarcasm definitely protected him, but also alienated him from people and kept him isolated. TC appeared to experience triumphant feelings when he - through his sneering and cynicism - put others down and maintained his dignity. Nevertheless, the cost was quite high: He had no choice but to endure the pain of social alienation.

\section{Treatment Plan}

\section{The Choice of Cognitive-Behavioral Therapy for TC}

Cognitive-behavioral therapy (CBT) was chosen as the major treatment modality in TC's case because of its known efficacy in treating depression and anxiety as well. In addition, as pointed out by Y. N. Lin (2001), CBT can be effective for treating anxiety and depressive disorders among the Chinese. Hodges and Oei (2007) suggest that one reason for the effectiveness is that the cognitive component in CBT is consistent with the pragmatic approach preferred by the Chinese culture. In fact, TC bought Albert Ellis' self-help books when TC was in high school, and he found that Ellis' theories made much sense to him. Secondly, like many other Asian-American clients, TC preferred the type of therapy in which new skills could be acquired (Sue \& Sue, 2003). According to research, many Asian-American clients do not return to therapy when the presenting problems have not been addressed directly, and when progress is not evident in the first few sessions (Sue \& Sue, 2003). Family therapy was also considered, as the family issues seemed closely related to TC's presenting concerns. However, family therapy was deemed unfeasible as TC did not want his family to know that he was in therapy.

\section{The Choice of Cognitive-Behavioral Therapy for TC}

As discussed above, Safran and Segal's (1990) cognitive-interpersonal style model was employed as a supplementary treatment modality in TC's case. This model was particularly 
Integrating Cognitive-Behavioral and Cognitive-Interpersonal Case Formulations:

A Case Study of a Chinese American Male

E.T. Liu

Pragmatic Case Studies in Psychotherapy, http://pcsp.libraries.rutgers.edu

Volume 3, Module 3, Article 1, pp. 1-33, 07-27-07 [copyright by author]

helpful in addressing TC's distinctive interactional style, which in turn created negative feelings and reactions in other people, whose feedback then reinforced TC's negative, depressiveinducing thoughts about himself.

Treatment Goals and Strategies for Addressing Them

Initial treatment goals and strategies for reaching them were developed collaboratively with TC, based on his present stressors and past history. The goals included:

1. Preventing suicide attempts -- by monitoring TC's suicidal ideation; by continuously assessing TC's risk, intent, and plan for suicide; and by having him sign and periodically renew a "no-suicide contract."

2. Decreasing depressive and anxiety symptoms -- by activity scheduling and monitoring; by cognitive-restructuring; and by a "metacommunication" strategy, i.e., by employing interventions involving explicit communication about therapist-client interactions.

3. Increasing the frequency of pleasant activities -- by activity scheduling and monitoring, and by setting pleasure goals using such tools as a "Pleasant Events Schedule" and a client log of moods and activities (Lewinsohn, Munoz, Youngren, \& Zeiss, 1992).

4. Improving social skills -- by role-plays, suggestions, and cognitive-restructuring; and by a metacommunication strategy.

5. Anger management -- by cognitive-restructuring and assertion training

\section{COURSE OF THERAPY}

\section{Overall Course of Treatment}

TC received weekly individual psychotherapy from me, and he saw a psychiatrist for medication. He took $100 \mathrm{mg}$ of the antidepressant Trazadone for about a year, and reported few unpleasant side effects. Individual therapy was conducted in English, as TC and I spoke different Chinese dialects. I saw TC a total of 41 times. He never missed any scheduled sessions.

\section{Developing a Collaborative Therapeutic Relationship in Light of TC's Off-Putting Social Behaviors}

Initially, the anxiety level in the room between TC and me was quite high. TC talked in a pressured, hypomanic-like manner, jumping from topic to topic. In the first session, he constantly moved his head from one side to the other, much like a pendulum. In fact, he only had eye contact with me for at most 2 or 3 seconds throughout the session, leading me to wonder about the underlying cause of such unusual behavior (e.g., anxiety, medical reasons, or a combination of both). The situation improved minimally in the second session. Such behaviors 
Integrating Cognitive-Behavioral and Cognitive-Interpersonal Case Formulations:

A Case Study of a Chinese American Male

E.T. Liu

Pragmatic Case Studies in Psychotherapy, http://pcsp.libraries.rutgers.edu

Volume 3, Module 3, Article 1, pp. 1-33, 07-27-07 [copyright by author]

would be construed as eccentric and inappropriate by most people, even after taking into account cultural factors like shyness. Thus I asked TC directly, "I noticed that you sometimes turn your head like this, it seems like you don't want to have any eye contact with me. Have you noticed that in yourself?" To my surprise, he replied, "Yeah, I know." TC acknowledged his anxiety when reporting personal things. Further, he stated that last year he did not do it as much because the previous therapist was "not female."

TC's thoughts and feelings towards me were very important, especially given the similarities in our age and ethnicity, and differences in gender and socioeconomic status. Keeping in mind that he had never had a girlfriend and that the female schoolmates he attempted to talk with generally did not seem interested in talking to him, I could see how my presence and continual interest in him might be both novel and positive, but also anxiety-provoking for him. In addition, he placed a great deal of emphasis on people's outward appearance, especially on the way people dress. The difference in our socioeconomic status, and consequently the difference in the way we dressed, likely triggered feelings of inadequacy in him.

Though TC turned his head less often and increased his eye contact a little after I addressed these behaviors with him directly, it was still an issue. I wondered if there was any other way to approach this. Following the advice of a supervisor, I moved our two chairs so that they were perpendicular to one another. TC no longer had to face me; the choice was given to him. The situation improved significantly; he stopped turning his head and would even turn his head to have eye contact with me sometimes. Over time, it seemed apparent that his head-turning was associated with anxiety. When anxiety-provoking topics came up in the session, TC would begin turning his head away from me. Further, in a later session when I moved my chair closer to his in order to show him a piece of paper, he looked anxious, talked faster, and began turning his head.

Another typical behavior was that TC interrupted me with no predictable patterns, which was also thought to be related to anxiety. TC also had the tendency to display a cynical facial expression - rolling up his eyes, raising his eyebrows, and sneering slightly. Additionally, he tended to make sarcastic remarks (e.g., saying "those wonderful passengers behind me" when in fact he meant "those annoying passengers from hell."). Both tendencies made it difficult for me to feel connected with him, and I hypothesized that both were closely related to his outlook, e.g., "Others are harsh and unfair"; and to his coping style, e.g., "Before you reject me, I'll reject you."

As the therapist, I had mixed feelings toward TC. I liked him as a client because he showed up for every session and engaged in the work of therapy. I also felt sorry for him and wanted to resolve his problems quickly for him. At the same time, however, I was aware that if he were not my client, I probably would not choose to have an extended conversation with him, and I could see how other people in his school might not find him to be a comfortable person to be around. I felt that my thoughts and feelings towards him as the client provided a window into the "real-world effects" that TC had outside of therapy: His eccentric and unpleasant behaviors 
Integrating Cognitive-Behavioral and Cognitive-Interpersonal Case Formulations:

A Case Study of a Chinese American Male

E.T. Liu

Pragmatic Case Studies in Psychotherapy, http://pcsp.libraries.rutgers.edu

Volume 3, Module 3, Article 1, pp. 1-33, 07-27-07 [copyright by author]

in fact annoyed and frustrated me, as they likely annoyed and frustrated other people in his life. (Note that psychoanalysis refers to the therapist's personal reactions to the client under the concept of "countertransference," while Persons (1989), a Beck-trained cognitive therapist, has discussed these reactions in a chapter titled, "Cognitive Therapy for the Cognitive Therapist.")

I found myself feeling alienated by TC's cynical facial expression and constant interruptions. Those behaviors felt like rejections and disrespect to me. Thankfully I came across two valuable books at the time -- Yalom's (2002) The Gift of Therapy, and Safran \& Segal's (1990), Interpersonal Processes in Cognitive Therapy. I was reminded that all exchanges that occurred in the therapy room were "grist for mill," and that my feedback could help him function better in the interpersonal arena. In the $16^{\text {th }}$ session, I finally decided to stop trying to hide my frustration and instead give him direct feedback (see the excerpt below ). In response, and much to my surprise, he actually became much more genuine and sincere. We then established a policy that we would be honest with our feelings, and would be more direct with each other in our communication. It felt satisfying that our connection was genuine, and that I was able to get through to him. In the later stage of the therapy, our relationship was more like collaborative "teammates" who tried to tackle his difficulties together.

\section{Cognitive-Behavioral Intervention}

\section{$\underline{\text { Behavioral Strategies }}$}

The focus of the first few sessions was on establishing rapport, reorienting TC to the collaborative nature of CBT, setting goals, and assuring the two of us of his safety (vis a vis his suicidal thoughts). I first explored what he already knew about CBT, which was a vague understanding of the connection between one's cognition and mood. I then proceeded to further educate him about the cognitive model, using an immediate example in the waiting room: his thought, "Other people my age don't have to be here," leading to feelings of sadness before the first session. Being aware of his feelings of shame and guilt associated with receiving mental health services, I normalized his experiences and provided psychoeducation. Additionally, I expressed serious concern about his suicidal ideation and safety, and introduced a "no-suicide contract" to him. We discussed the terms of the contract in detail.

In the fourth session, TC willingly signed the contract and stated,

You don't have to worry; it's not like that I can find a fast, secure, and reliable way to die. I don't want to end up being in a worse condition, having more broken bones or something. What I have is already bad enough.

It should be noted that the "no-suicide contract" was employed as a clinical tool, not a legal tool. The language of the no-suicide contract developed by Bongar (1996) has been found to be acceptable to many clients. Following the initial discussion on suicide, I continued to assess TC for suicidal intent and plan on a consistent basis. 
Integrating Cognitive-Behavioral and Cognitive-Interpersonal Case Formulations:

A Case Study of a Chinese American Male

E.T. Liu

Pragmatic Case Studies in Psychotherapy, http://pcsp.libraries.rutgers.edu

Volume 3, Module 3, Article 1, pp. 1-33, 07-27-07 [copyright by author]

Subsequently, we started having more discussion on the interconnections among TC's thoughts, feelings, and behaviors; and some behavioral interventions were introduced to strengthen the understanding. As Beck, Rush, Shaw, \& Emery (1979) point out, it is advisable to work on behavioral changes of a depressed client before tackling cognitive change, as subtle cognitive distinctions and changes may be difficult to comprehend at first. Activity monitoring was introduced and assigned as homework. TC used a "Mood/Activity Monitor Log" (a chart with days of the week across the top and each hour down the left-hand side) to track his activities throughout the day and to rate them for feelings of depression and anxiety. In reviewing the completed logs, we discussed his tendency to feel worse (mood) when staying at home and doing nothing (activity) and to feel better (mood) when getting out and doing something (activity).

In addition, using the "Pleasant Events Schedule," a list of events that have been found to be potentially pleasurable for individuals developed by Lewinsohn and his associates (1992), TC identified some activities that he thought were pleasurable and would like to do more, such as going to the beach, taking tests when well prepared, and planning trips or vacations. In a similar vein, I asked him to create and accomplish a "pleasure goal" (e.g., eating delicious food) and a "mastery goal" (e.g., reading a chapter) everyday. Identifying and scheduling pleasure and mastery activities was important. These behavioral methods helped TC recognize how his life had gotten out of balance; many things he used to enjoy (e.g., listening to pop music) were no longer part of his daily activities. In fact, his habitual activities did not provide much emotional nourishment or positive reinforcement. Mastery and pleasure goals worked by providing direct evidence to disconfirm his automatic thoughts such as, "I am hopeless -- unable to do anything or unable to enjoy anything."

Lastly, we also planned an activity that would not only help him take a step forward from his current activity level but also help with his knee pain -- doing exercises on the exercise bike in his apartment. Persons (1989) states that especially in the beginning of treatment, physical exercise can be helpful because it is concrete, can be done in small quantity, and brings immediate gratification.

TC's compliance with homework varied. While he completed the Mood/Activity Monitor Log and accomplished at least 3 mastery goals everyday, TC had more difficulty accomplishing the physical exercises and pleasure goals. He blamed himself for not doing as much exercise as he wanted to $(10-15$ minutes per day), and he seemed to regard the pleasure goals as redundant. In response, I directly suggested TC reduce his expected time of exercise per day, and I guided him in problem-solving (predicting obstacles, exploring possible solutions, and preventing the obstacles from interfering with the new plans, e.g., finding the best time to exercise) to address the issues with exercise and pleasure goals. Furthermore, as I saw that he was completing more than enough mastery tasks (e.g., he spent most of his time studying in the hotel room on a rare trip abroad as he pressured himself to get through at least three chapters everyday) and had evidently grasped the connection between mastery and positive mood, I suggested that he shift his focus away from the mastery goals. Mastery goals were then taken off the list of homework assignments. 
Integrating Cognitive-Behavioral and Cognitive-Interpersonal Case Formulations:

A Case Study of a Chinese American Male

E.T. Liu

Pragmatic Case Studies in Psychotherapy, http://pcsp.libraries.rutgers.edu

Volume 3, Module 3, Article 1, pp. 1-33, 07-27-07 [copyright by author]

To address TC's sleep problems, I taught TC diaphragmatic breathing, and I gave him an audiotape with 10 minutes of progressive muscle relaxation training.

Bibliotherapy was also incorporated in the early sessions. I assigned him reading from the social skills training chapter of a self-help book (Burns' 1989, The Feeling Good Handbook) as homework, and we discussed his reactions and questions to the reading in the session. A few weeks into the treatment, after he had done the reading, he began greeting me with a smile, which was accompanied by, "How are you doing?" or "How's your day going?" At the end of sessions, he always said to me, "Thank you very much for everything" or "Thank you for your time." TC seemed to be working hard to acquire and practice social skills, and I tried to model appropriate social behavior and to positively reinforce his efforts with a smile and a friendly response.

As these other activities were proceeding, I set up roleplays with TC in which he interacted with a "rude, unfair professor" and an "unfriendly classmate." I first played "TC" and modeled, and then switched roles with him, gave him feedback, after which we would practice the interactions a few more times. The roleplays were useful for TC, who had weak social skills in general. Most often, TC knew what he wanted to do, but had no idea how to go about it. At the end of roleplays, TC was better prepared to conduct behavioral experiments in the outside world.

\section{Cognitive Strategies}

In discussing these situations, I also used the thought record forms from Greenberger and Padesky's (1995) book, Mind over Mood, and helped TC to learn how to identify his automatic thoughts. Through Socratic dialogue, TC and I uncovered his underlying conditional and core beliefs, and we discussed the cognitive distortions that characterized his cognition (e.g., "discounting the positives," "mind-reading," "overgeneralization," and "fortune-telling").

I had particular difficulty in challenging certain of TC's dysfunctional and self-defeating thoughts, e.g., "I am not good enough." As mentioned earlier, TC reported some thoughts that appear to stem from the Chinese values of achievement and humility, such as: "One has to work very hard and shall not be content with oneself even when things are going well. One needs to be modest and always anticipate potential setbacks." TC clearly indicated that if he started to be more optimistic and think about everything in more positive terms, he would have low expectations for himself and would not be able to function at his best. Such difficulty also seemed to be related to his problem with pursuing pleasure goals. In the Concluding Evaluation section below, in a discussion of "Culture-Specific Challenges," I present some more specifics as to how I dealt with TC's self-defeating thoughts about not being good enough. 
Integrating Cognitive-Behavioral and Cognitive-Interpersonal Case Formulations:

A Case Study of a Chinese American Male

E.T. Liu

Pragmatic Case Studies in Psychotherapy, http://pcsp.libraries.rutgers.edu

Volume 3, Module 3, Article 1, pp. 1-33, 07-27-07 [copyright by author]

\section{Intervention Based on the Cognitive-Interpersonal Cycle Model}

The therapeutic relationship was used explicitly as a therapeutic tool, rather than as merely the context in which successful cognitive-behavioral interventions occurred. In the above section, "Developing a Collaborative Therapeutic Relationship in Light of TC's Off-Putting Social Behaviors ," I described the behaviors that were "pulled" from me by TC's behavior. Knowing that I did not want to unwittingly participate in a dysfunctional interpersonal cycle in which I acted out the feeling of being annoyed or alienated by TC, I began a "disengagement process." I used the occurrences in the here-and-now of the therapy room, identified my own feelings, and told TC explicitly, e.g., "I feel distanced when you do not respond to me directly."

The following excerpt from mid-way in the 16th session illustrates TC's dysfunctional interpersonal behaviors expressed in the here-and-now of the therapy relationship and my attempts to bring them to light. The session began with TC showing me the voluminous homework he did (three pages of automatic thoughts triggered by an upsetting situation at his cousin's house). When I explored further, however, he began to talk incessantly about two other familiar stories, neither of which had to do with the upsetting situation in question.

T[herapist]: I am wondering... what's happening between us now that you are not responding to me directly?

C[lient]: Oh ..... nothing, nothing. (looks at the thought record) So, what's next, let's take a look at the thought record.

T: Do you know... (cut off by client)

C: It's nothing. You want me to read the "automatic thoughts" on this thought record to you?

T: Well, TC, let's pause here for a second. Do you know what happens to me when you don't respond to me directly?

C: Oh yeah (rolls up his eyes and sneers)... disappointed and angry, and what else....

T: I am glad that I checked with you, 'cause that's not how I was feeling. Let me tell you what happens to me. I feel distanced. It's like we are in this team together, yet I am shut out by you.

C: Well, I cannot read your mind.

T: (smiles because "mind-reading" is one of the cognitive distortions that we have looked at). Good point. That's why I thought I'd share with you and tell you directly how I felt.

C: (looks anxious and turns his head) So what do we work on next? 
Integrating Cognitive-Behavioral and Cognitive-Interpersonal Case Formulations:

A Case Study of a Chinese American Male

E.T. Liu

Pragmatic Case Studies in Psychotherapy, http://pcsp.libraries.rutgers.edu

Volume 3, Module 3, Article 1, pp. 1-33, 07-27-07 [copyright by author]

T: TC, you know, I think it's true that other people are unfair to you and treat you badly. And part of the reason why you are here in therapy is that you are not happy with the way people interact with you ... (interrupted)

C: Well, that's irrational thinking, or (trying to think of the term, and laughs nervously) ...

T: Wanting to have satisfying interactions with others is not irrational thinking. In fact, everyone wants that! And I hope that by directly talking about what the relationship is like between you and me, we can see how that parallels other relationships in your life, which is where you'd like to get more satisfaction, right?

C: (looks down) Yeah...

T: What's going through your mind now?

C: Oh nothing, nothing...

$\mathrm{T}$ : Any guesses?

C: (rolls up his eyes) Our relationship is good. Therapy is going well. It is at least above average (sneers). I am here every week. Otherwise I wouldn't be here. (laughs nervously)

T: The feedback sounds nice, but as the recipient, I also find it very confusing. While you said that therapy is good and that our relationship is fine, you also rolled up your eyes and sneered a little. I got confused by what you were communicating to me.

C: (pauses and looks down) I guess I am just not a good actor, not like other people. .

T: By "not being a good actor," what do you mean?

C: Well, I let my true feelings come out.

T: Let's say that you do let your true feelings come out, what's the worst thing that could happen?

C: (laughs) Oh well, nobody does that. It's not the... socially acceptable way. People don't talk direct, especially at work, nobody will tell you what they really think.

T: But if you do show your feelings and express yourself directly, what are you afraid might happen?

C: Nobody will like me. So I learned, I learned.

T: When you speak to me more from your heart, like what you are doing now, I wonder, what's your level of connection to me? 
Integrating Cognitive-Behavioral and Cognitive-Interpersonal Case Formulations:

A Case Study of a Chinese American Male

E.T. Liu

Pragmatic Case Studies in Psychotherapy, http://pcsp.libraries.rutgers.edu

Volume 3, Module 3, Article 1, pp. 1-33, 07-27-07 [copyright by author]

C: (silent)

T: I am feeling different now than I did at the beginning of the session. I feel closer to the real you.

C: (looks at me questioningly)

T: Let's look at your thought, "Nobody will like me if I let me true feelings come out." Sounds like based on your past experiences, you can find much evidence that supports this thought. But I am wondering, have you had any experiences that show that this thought may not be completely true $100 \%$ of the time?

C: (silent) I had a pretty good talk with my sister. I sometimes ask her questions. And that one time, it went pretty well.

T: In this conversation, did you let your true feelings show and talk from your heart?

C: Yeah (takes off glasses, rubs his eyes, and puts glasses back on)

T: And you felt connected to your sister?

C: Yeah, I did.

T: How did your sister respond to you?

C: She was kind of nice, didn't criticize me or anything. that day?

T: Do you get a sense that she felt closer to you, and that she liked talking to you

C: (nodded) I guess so.

In this session, I focused on the here-and-now and used Socratic questioning to facilitate metacommunication, i.e., communication about the therapist-client interactions (Safran \& Muran, 2000). As shown, I wondered out loud about my observation of TC's behaviors, and shared my feelings of confusion when being in the room with him. According to Safran and Muran (2000), the goal of metacommunication is to invite the client into a collaborative exploration of what might have unwittingly transpired in the interpersonal transactions.

I guided TC to look at the maladaptive nature of his typical behaviors. He had the firm belief that people close to him would not value him, so he expected rejection. The attempted solution (disguising his vulnerable feelings and acting cynically) became his problem (a lack of satisfying interpersonal relationships). The characteristic themes that came up in therapy were that he was uncared for and unfairly treated by others. Here an example of a self-fulfilling 
Integrating Cognitive-Behavioral and Cognitive-Interpersonal Case Formulations:

A Case Study of a Chinese American Male

E.T. Liu

Pragmatic Case Studies in Psychotherapy, http://pcsp.libraries.rutgers.edu

Volume 3, Module 3, Article 1, pp. 1-33, 07-27-07 [copyright by author]

prophecy was evident: He so dreaded being rejected that his behavior brought about that very thing.

Having recognized this pattern, I provided feedback gently. It was through feedback that TC learned to be a better witness to his own behaviors, and to appreciate the impact of his behaviors upon the feelings of others. TC believed that others would be repulsed by him if he let his true self come out. Thus, I made sure that I did not convey discomfort when he appeared vulnerable in front of me. I gave him direct feedback to help him become aware of how his behaviors influenced others' feelings. I think he understood that I was honestly trying to clarify my own feelings and to share them in a way that was exploratory, rather than derogatory. Importantly, the closeness of the therapy relationship not only taught social skills, but also served as a strong piece of counter-evidence to his long-held dysfunctional thought, "Nobody will accept me if I let my true self come out."

\section{Termination}

The therapeutic relationship between TC and myself ended as I completed the year-long training at the agency. When the therapy ended, TC was transferred to another intern. During the course of therapy, he knew that I would leave in a certain amount of time, and we frequently checked in with each other about how therapy was going. I was acutely aware that certain negative thoughts (e.g., "I am not important," "She will abandon me and move on," and "No one really cares about me") might have been going through his mind. Hence, aside from expressing my real feelings of sadness and regret about having to end the therapy, I felt the need to prepare him for the termination and the transition to another therapist.

In the final sessions, I reminded him that the tools and techniques that he had acquired were things that he could use to help himself. As I reviewed the tools with him, his sense of resourcefulness increased, e.g., he remarked, "It is kind of nice that I can now use these forms and try to help myself feel better." We also anticipated and prepared for his negative thoughts around termination, e.g., "Is the therapist leaving me because I am not important or good enough?" "Did she fake her caring and supportive attitude throughout the treatment?" and "I am definitely going to be depressed again! -- Is there a cognitive distortion in this thought?" We then discussed how would he respond to them, and what might be a more functional or more realistic thought.

It was the agency's policy that all therapies end in an "absolutely clean" manner, with no further contact between client and former therapist, based on the rationale that this would best protect the therapeutic relationship between a client and his or her current therapist. This meant that I was not able to follow-up on TC once we had terminated. While this lack of opportunity for follow-up is disappointing to me, I am grateful that during the therapy I shared a special journey with TC, in which both of us worked hard. I continue to hold hopeful expectations for him. 
Integrating Cognitive-Behavioral and Cognitive-Interpersonal Case Formulations:

A Case Study of a Chinese American Male

E.T. Liu

Pragmatic Case Studies in Psychotherapy, http://pcsp.libraries.rutgers.edu

Volume 3, Module 3, Article 1, pp. 1-33, 07-27-07 [copyright by author]

\section{THERAPY MONITORING AND THE USE OF FEEDBACK INFORMATION}

As mentioned earlier, one source of monitoring was provided by ongoing clinical supervision of the case. In addition, a number of readings - associated with the three models outlined above in the "Guiding Conception" section -- were most helpful. Of particular relevance were readings by J. Beck (1995); Burns (1989); Greenberger and Padesky (1995); Persons (1989); Persons, Davidson, and Tompkins (2001); Safran and Segal (1997); and Yalom (2002).

In addition, upon the encouragement of one of my clinical supervisors, I began keeping a journal of personal reactions to my clients. The journal helped me to become aware of the potential effects - negative and positive -- that my personal reactions might have had on the treatment. Essentially, my own feelings and reactions to TC were treated as crucially important data that enabled the exploration of his cognitive-interpersonal cycle in greater detail.

As a result of continuous supervision and self-monitoring, there were many times that I specifically modified my intervention based on TC's response. Some examples include:

A. Re-arranging my chair and TC's chair in the therapy office at a 90 degree angle.

B. Taking "mastery goals" off the list of homework assignments, when I found out that TC already set up too many "mastery goals" for himself.

C. Reducing the amount of exercise assigned.

D. Initiating metacommunication about the therapeutic relationship in a persistent manner, even when TC initially tried to evade such communication.

\section{CONCLUDING EVALUATION OF THE THERAPY'S PROCESS AND OUTCOME}

\section{Observed Changes - In the Therapy Office}

In the latter part of the therapy, TC took the risks in the therapy relationship by showing me his real self, with significantly less cynical facial expressions and fewer sarcastic remarks. He always greeted me with a genuine smile, and ended with appreciative remarks. I felt that the quality of TC's appreciative remarks changed from somewhat machine-like in the beginning, to much more authentic, at the end. While TC did not grow into a gregarious or a warm individual, he certainly became much more likable and approachable. With normal eye contact, TC seemed much more at ease when interacting with me. Although the difference in our socioeconomic status was not directly addressed in therapy, TC seemed to be more comfortable with himself and with me. He sometimes chose to dress up, and other times he would wear jeans and sweatshirt. I 
Integrating Cognitive-Behavioral and Cognitive-Interpersonal Case Formulations:

A Case Study of a Chinese American Male

E.T. Liu

Pragmatic Case Studies in Psychotherapy, http://pcsp.libraries.rutgers.edu

Volume 3, Module 3, Article 1, pp. 1-33, 07-27-07 [copyright by author]

felt that the anxiety level in the room was low. He appeared much more comfortable about showing vulnerabilities, and voluntarily showed me the pictures of his cluttered apartment. The risks he took in the therapeutic relationship allowed him to venture out and interact with other people in his life.

\section{Reported Changes - Outside the Therapy Office}

In the later stage of therapy, TC reported that he made phone calls to a few friends from college when he felt lonely and found himself feeling better afterwards. Further, he asked for a classmate's help in understanding the professor's instructions. Once in the computer lab, he asked for a girl's phone number and obtained her e-mail address. In addition, before he left for his sister's wedding abroad, he obtained a female classmate's agreement to audiotape the lectures for him, after being rejected by two other classmates. Further, he made some progress on "pleasure goals," accomplishing three to four a week (e.g., watching a good movie when his mother was not home; going for a drive on a sunny day; listening to music; and having a phone conversation with a friend once a week). He also reported that he purchased a multi-function exercise machine and a CD collection of China pop music from the 80 's, and that he felt good about his decisions.

Also, TC showed substantial progress on his presenting symptoms. Specifically, as shown in Tables 1 and 2, at the end of therapy (in the 40th session), TC's score on the Burns anxiety measure had gone down from 30 (moderate anxiety) at the beginning of therapy to 16 (mild anxiety) at the end; and his score on the Burns depression measure, from 31 (severe depression) at the beginning, to 15 (mild depression) at the end. In addition, TC reported significant improvement in the quality of his sleep (changing, on a 10-point scale, from a 3 at the beginning to a 7.5 at the end of therapy, as indicated in Table 2). Finally, as indicated in Table 3, TC reported an improvement of grades in his classes in the second semester towards the end of therapy -- a positive change about which he was quite excited.

\section{Treatment Implications for the Case}

The cognitive-behavioral and cognitive-interpersonal interventions led to positive outcomes. Due to TC's heightened sensitivity to criticisms, he was more receptive to the gentle Socratic method than a confrontational approach. Other than the fact that he was more likely to believe something if he arrived at the conclusions by himself, over the course of therapy, he also learned to ask himself Socratic questions in distressing situations, such as, "What thoughts am I having in this situation?" "How do these thoughts make me feel?," "What does that say about me, other people, and the future?," "What does it mean to me?," "Is there another way to think about this situation that would help me feel better and function better?," and "What's the worst thing that might happen if this thought is true?" 
Integrating Cognitive-Behavioral and Cognitive-Interpersonal Case Formulations:

A Case Study of a Chinese American Male

E.T. Liu

Pragmatic Case Studies in Psychotherapy, http://pcsp.libraries.rutgers.edu

Volume 3, Module 3, Article 1, pp. 1-33, 07-27-07 [copyright by author]

\section{Culture-Specific Challenges}

In reporting his accomplishments, TC would often qualify his progress and success with statements such as, "Oh, it was nothing," "It was not important," or "I didn't do that well." He would then proceed to focus on the negative parts of the incidents, e.g., he said that the female classmate who agreed to audiotape for him appeared somewhat annoyed when she agreed.

The case appears to highlight a culture-specific challenge in doing CBT with clients of Chinese origin. Beliefs such as "I am not good enough" were difficult to challenge, for they served motivating functions for TC. Certain beliefs may be drawing from aspects of Chinese cultural values such as achievement and humility. As with all cultural values, while these values are not problematic in and of themselves, they may become dysfunctional when rigidly held.

"Family recognition through achievement" was discussed previously (see "CBT case formulation - origins"). In most Chinese families, parents hold high expectations for their children to excel both academically and occupationally (Stevenson \& Lee, 1996), viewing children's high achievement as the direct result of successful parenting (K. Lin, 2003). In fact, it has been pointed out that for Chinese individuals, achievement is desired primarily because it serves the purpose of honoring the family (Y. N. Lin, 2002; D. Sue, 1997).

While the emphasis on achievement is worth noting, another cultural value "humility" -- appears to be more related to the culture-specific challenges in doing CBT with clients of Chinese origin, as discussed in this case report. Thus, a more in-depth discussion on "humility" is warranted. In the subsequent paragraphs, relevant empirical findings will be presented first, after which I would like to venture some personal observations that, to the best of my knowledge, have not been discussed in the literature.

Humility is the virtue of always being humble, modest, and never boastful (Kim et al., 1999; Kim et al., 2001). Some Chinese proverbs -- for example those that translate as "the humble gentleman," "great attitudes come from humility," and "criticism arises with arrogance, while benefit always comes with humility" -- appear to demonstrate the value of humility in the Chinese culture (K. Lin, 2003). Humility has been found to be important for maintaining interpersonal harmony (Y. N. Lin, 2002). On the other hand, being too proud of oneself is likely to invite harm and criticism from others, and to create distress in others, which would all lead to an undesirable outcome -- disruption of interpersonal harmony (K. Lin, 2003). Given the welldocumented cultural emphasis on collectivism (Kim, Trandis, Katiticibasi, Choi, \& Yoon, 1994; Tweed \& Lehman, 2002; Yang, 1986), researchers appear to concur that the Chinese culture encourages humility and discourages self-centeredness for the maintenance of interpersonal harmony (Chen \& Davensport, 2005, K. Lin, 2003; Y. N. Lin, 2002).

Research evidence supporting the modesty effect in Chinese children has also been reported. In a study by Lee, Xu, Fu, Cameron, and Chen ( 2001), Taiwan Chinese, Mainland Chinese and Canadian children were evaluated on their categorization and evaluation of truth- 
Integrating Cognitive-Behavioral and Cognitive-Interpersonal Case Formulations:

A Case Study of a Chinese American Male

E.T. Liu

Pragmatic Case Studies in Psychotherapy, http://pcsp.libraries.rutgers.edu

Volume 3, Module 3, Article 1, pp. 1-33, 07-27-07 [copyright by author]

and lie-telling in situations involving pro- and antisocial behaviors. It was found that as age increased, Taiwan Chinese and Mainland Chinese children gave increasingly less positive ratings to a story character who does something good and tells a teacher about it, and increasingly positive ratings to a story character who lies about, i.e., covering up his/her good deed (Lee et al., 2001). The pattern was not observed in Canadian children. Lee et al. (2001) suggested that the findings reflect the impact of the Chinese culture's emphasis on self-effacement and modesty, and that since similar findings were obtained in both Taiwan Chinese and Mainland Chinese samples, it appears that the traditional Chinese value of modesty is deeply rooted in Chinese societies, and is likely to be part of what theorists (Huang, 1987; Su, 1993) have referred to as the deep structure of the Chinese culture.

Therefore, humility, modesty, and self-effacement appear to be rooted in the Chinese culture, and by the time they graduate from elementary school, most Chinese children will have adopted these values (Lee et al., 2001). Yet, in what way does humility pertain to the difficulty in challenging the client's rigidly held belief, "I am not good enough"? Here, I would like to raise the possibility that aside from the motivating function of maintaining interpersonal harmony, as noted in the literature, there may be another factor behind this cultural emphasis on humility. The personal observations I venture below are based on my experiences and interpretations, and as such, no definitive conclusions may be drawn. Empirical research is needed to shed more systematic light on this topic.

It is my observation that "fear of personal failures" may account for the humble attitudes that Chinese individuals adopt when they face success. Here I am referring to the relatively "private" moments, when Chinese individuals are by themselves, or in the therapy office, as opposed to public settings, where one's success is announced in front of others. The observation appears to be illustrated in a well-known Chinese proverb, which can be translated as, "The proud will eventually fail." It means that those who are complacent and proud are very likely to face unforeseen catastrophes and fail bitterly (Global Chinese Language and Culture Center, 2005). In growing up, many Chinese children seem to be socialized to believe that if they allow themselves to be satisfied with their current conditions and to become proud of their accomplishments, they will eventually face the undesirable outcome - personal failures.

The cautionary message has also been conveyed by Dharma Master Venerable Hsing Yun (2006). He stated:

[Translated] When you succeed, it is important not to be proud and complacent.

You should remember the lessons you had learned from previous failures. You should not forget that once you slack off, you may find yourself on the path to failures.

An underlying message here appears to be that one should maintain vigilance even when things are going well. What is suggested in the Buddha master's reminder may not be unfamiliar to most individuals of Chinese origin. In therapy, TC recounted an incident in which he, as a child, happily told his mother that he obtained good grades in school, and was immediately told that he should not be too proud of his accomplishments. He indicated that he learned early on 
Integrating Cognitive-Behavioral and Cognitive-Interpersonal Case Formulations:

A Case Study of a Chinese American Male

E.T. Liu

Pragmatic Case Studies in Psychotherapy, http://pcsp.libraries.rutgers.edu

Volume 3, Module 3, Article 1, pp. 1-33, 07-27-07 [copyright by author]

that if he allowed himself to be happy with his current condition, then his life might not get better, or that it might take turn for worse.

Some thoughts that TC reported (e.g., "Keep telling yourself that you are not good enough; don't ever be satisfied with your accomplishments") may be related to the fear of personal failures. These thoughts may have contributed to TC's depression and anxiety, yet at the same time, they also seemed to motivate this self-disciplined man to become a more successful person. Essentially, having an exclusively negative focus on himself had pushed TC to work extra hard in order to be better; and thus in some ways his self-introspection and self-awareness of "not being good enough" had enabled him to get ahead, despite his circumstances. Similarly, constantly thinking about the future, predicting and planning for the worst, and being constantly vigilant had also served him well in some ways. For example, when he found out that he would have to enroll in a difficult course next semester, he would get himself ready for the upcoming stressor by obtaining the syllabus, buying the assigned books, and reading them prior to actually taking the course. As a result of the painstaking preparatory efforts, he was more likely to get a high, satisfying grade in difficult courses.

Thus, in examining TC's depressive thoughts from a "validity" standpoint, I could explore the extent to which the actual evidence confirmed the beliefs. However, when examining the "utility" or the "function" of such beliefs, I often encountered TC's overt objection, "But I think this thought is very useful! I don't want to let it go! That won't be good for me!"

Being familiar with these cultural values, the first thing I did was to validate TC. I normalized the pressure he experienced, and I said to him, "It's really hard when you are constantly given the strong cultural message that you should never be satisfied with yourself." He seemed to appreciate the validation. I then emphasized to him that in the Chinese culture, there is also the value of seeing the "whole" (positive, neutral, and negative) rather than just the "parts" (negative only) (Koenig \& Spano, 1998; Walsh, 1989). With the exclusive negative focus, he was discounting the positives, and was seeing the "parts" only. He seemed to appreciate the reminder that was anchored in the Chinese perspective, he responded with a smile and said, "Yeah, that's true."

Furthermore, we examined the function of the beliefs. Were these beliefs useful for him? There was a reason why he was holding onto the beliefs, because they had enabled him to accomplish much. However, were the beliefs helpful and adaptive all the time? We talked about how they often added more stress to his life, and that in many instances they had prevented him from functioning at an optimal level. In that regard, theses beliefs were certainly more detrimental than beneficial.

Since doing therapy with TC, I have worked with many other clients with Chinese origin. With these clients, I have frequently encountered similar cultural issues and themes. In response, I have found it best to be supportive, to respect the client's view, and to allow the client to process thoroughly the various ways in which these beliefs have helped them. Thus, following 
Integrating Cognitive-Behavioral and Cognitive-Interpersonal Case Formulations:

A Case Study of a Chinese American Male

E.T. Liu

Pragmatic Case Studies in Psychotherapy, http://pcsp.libraries.rutgers.edu

Volume 3, Module 3, Article 1, pp. 1-33, 07-27-07 [copyright by author]

Padesky and Greenberger's (1995) admonition that "evidence disconfirming the 'hot' thought" should be explored only after the "evidence confirming the 'hot' thought" has been thoroughly processed and examined," I have found it most useful to put off for a while the discussion about how these self-defeating beliefs have hindered the client. Though clinicians may often find themselves feeling impatient and wishing to proceed with the "real" business of cognitive restructuring, they should always remind themselves that -- "slow is fast, and fast is slow."

Recently, some research has examined the use of CBT with Chinese American clients. Hodges and Oei (2007) reported a high degree of compatibility between CBT and the common values of the Chinese culture (e.g., individualism-hierarchy, orderly autonomy, disciplineassertion), and suggested that with some modifications, CBT should be more effective than newly developed indigenized therapies. In addition, Hwang et al. (2006) have done a systematic review of the experimental and clinical literature about conducting CBT with Chinese Americans, and derived 18 principles for understanding and enhancing such treatment. These include:

1. Initially educating Chinese American clients about the nature of therapy to reduce the likelihood of premature dropout.

2. Being sensitive to the client's cultural background.

3. Establishing explicit, concrete treatment goals with ongoing indicators of them.

4. Focusing on the psychoeducational aspects of treatment and linking therapy to the importance of education that is part of the Chinese culture.

5. Culturally bridging CBT concepts to Chinese cultural beliefs.

6. Having the therapist present him or herself as an expert authority figure.

7. Carefully clarifying client and therapist roles and expectations.

8. Taking into account cultural differences in how Chinese clients relate to authority figures

9. Joining with the client by "finding out more about them, their migration histories, and their family backgrounds" (p. 297).

10. Taking into account the very family-oriented nature of Chinese culture.

11. Being aware of the "shame and stigma associated with having a mental illness" (p. 297).

12. Being sensitive to the fact that Chinese clients are less comfortable talking about their feelings to the therapist. 
Integrating Cognitive-Behavioral and Cognitive-Interpersonal Case Formulations:

A Case Study of a Chinese American Male

E.T. Liu

Pragmatic Case Studies in Psychotherapy, http://pcsp.libraries.rutgers.edu

Volume 3, Module 3, Article 1, pp. 1-33, 07-27-07 [copyright by author]

13. Being aware of the "push-pull feelings and culture-related role inconsistencies that may exist between a client's culture of origin and the culture of therapy" (p. 298).

14. "Finding ways to integrate extant cultural strengths and healing practices into the client's treatment plan ... [as] one way to modify CBT to be more culturally sensitive and effective" (p. 298).

15. Being aware of how "ethnic differences in expression of distress can . . . [affect] diagnostic accuracy and treatment planning" (p. 298).

16. Being aware that Chinese clients can experience the emotional and cognitive symptoms of depression.

17. Helping clients to understand the relationships between "biomedical and psychosocial models of disease development" (p. 299).

18. Linking for some clients the connection between traditional forms of healing and behavioral treatments to motivate clients to engage clients in healthy behaviors and exercise.

These principles were recently published, yet many of them were incorporated into my treatment of TC. Though TC and I share a similar ethnic background, I made an effort to learn more about his specific cultural beliefs, cultural practices, and family background (Principle $2 \&$ Principle 9). It should be noted that a potential downside of the therapeutic dyad's sharing cultural similarities is that the therapist may stop being curious, and make assumptions that are not true for the client. One example was the Chinese New Year. I initially felt that it was natural for me to ask TC, "How was your time with your family? Did you have a good time with them?" But then I caught myself, thinking that I should not assume that he spent the night with his family. Therefore, instead, I asked him, "How was your New Year's Eve?" He said that it was fine, peaceful, and quiet. As it turned out, he had dinner by himself, studied, and went to bed early. While it may sound sad, it was actually not that bad for TC. As he indicated, when comparing the solitude to the tumultuous New Year's Eve on which TC - as a child - endured his parents' violent quarrels, he seemed to appreciate the serenity on this Chinese holiday.

The application of other principles should also be noted. As previously described, in the therapy I helped TC set up concrete, observable goals and ongoing indicators of improvement, which increased his perceived self-efficacy and strengthened the therapeutic relationship (Principle 3). I also addressed his feelings of shame and guilt associated with receiving mental health services by normalizing his experiences and providing psychoeducation (Principle 11). Further, I linked certain CBT concepts (e.g., "do not use a "mental filter"') to Chinese cultural values (e.g., the value of seeing the "whole" rather than just the "parts") (Principle 5). Lastly, as suggested in Principle 16 and demonstrated in TC's case, though the precipitant and initial complaint may involve physical discomfort (e.g., knee pain), Chinese clients are, in fact, capable 
Integrating Cognitive-Behavioral and Cognitive-Interpersonal Case Formulations:

A Case Study of a Chinese American Male

E.T. Liu

Pragmatic Case Studies in Psychotherapy, http://pcsp.libraries.rutgers.edu

Volume 3, Module 3, Article 1, pp. 1-33, 07-27-07 [copyright by author]

of fully experiencing and expressing the cognitive and emotional symptoms of depression (Principle 16).

Aside from these, when working with Chinese American clients, it is important that therapists not stereotype them (Hwang, 2006). Further, cultural strengths should also be given attention (Hwang, 2006). For example, in TC's case, perseverance and hardiness likely contributed to his working hard in therapy and achieving positive outcome at the end.

\section{Conclusion}

As shown in this case report, the integration of cognitive-behavioral and cognitiveinterpersonal approaches can be effective. This report aims to remind cognitive therapists to pay closer attention to their personal reactions to a client's in-session behaviors, and to utilize the here-and-now data in the exploration and modification of the client's thoughts and behaviors. Furthermore, when confronted with culture-specific challenges in Chinese American clients, with guidance, practice, and patience, this case is illustrative of how therapists can help clients learn how to respond more effectively to the self-defeating voices of the mind.

\section{REFERENCES}

American Psychiatric Association (1994). Diagnostic and statistical manual of mental disorders, $4^{\text {th }}$ ed. Washington, D.C.: American Psychiatric Association.

Barlow, D. H., Craske, M. G., Cerney, J. A., \& Klosko, J. S. (1989). Behavioral treatment of panic disorder. Behavior Therapy, 20, 261-282.

Beck, A. T. (1964). Thinking and depression: II. Theory and therapy. Archives of General Psychiatry, 10, 561-571.

Beck, A. T. (1976). Cognitive therapy and the emotional disorders. New York: International Universities Press.

Beck, J. S. (1995). Cognitive Therapy: Basics and beyond. New York: Guilford Press.

Beck, A. T., Rush, A. J., Shaw, B.F., \& Emery, G. (1979). Cognitive therapy of depression. New York: Guilford Press.

Bongar, B. (1996). The suicidal patient: Clinical and legal standards of care. Washington, DC: American Psychological Association.

Burns, D. D. (1989). The feeling good handbook. New York: Plume.

Butler, G., Fennell, M., Robson, D., \& Gelder, M. (1991). Comparison of behavior therapy and cognitive-behavior therapy in the treatment of generalized anxiety disorder. Journal of Consulting and Clinical Psychology, 59, 167-175.

Chen, S. W., \& Davenport, D. S. (2005). Cognitive-behavioral therapy with Chinese American clients: Cautionsand modifications. Psychotherapy: Theory, research, practice, training, 42 (1), 101-110.

Coyne, J. C. (1976). Depression and the response of others. Journal of Abnormal Psychology, 85, 186-193. 
Integrating Cognitive-Behavioral and Cognitive-Interpersonal Case Formulations:

A Case Study of a Chinese American Male

E.T. Liu

Pragmatic Case Studies in Psychotherapy, http://pcsp.libraries.rutgers.edu

Volume 3, Module 3, Article 1, pp. 1-33, 07-27-07 [copyright by author]

Dobson, K. S. (1989). A meta-analysis of the efficacy of cognitive therapy for depression. Journal of Consulting and Clinical Psychology, 57, 414-419.

Ellis, A. (1962). Reason and emotion in psychotherapy. New York: Lyle Stuart.

Epictetus (100 A.D.). Words to Live By [Online], http://www.angelfire.com/ca3/kurgan/quotes.html (retrieved September 2, 2006).

Giles, T. R. (Ed.). (1993). Handbook of effective psychotherapy. New York: Plenum Press.

Global Chinese Language and Culture Center (2005). Bi-weekly [Online], http://edu.ocac.gov.tw/culture/biweekly/animation3/444_d3/ (retrieved March 25, 2007).

Greenberger, D., \& Padesky, C. (1995). Mind over mood: A cognitive therapy treatment manual for clients. New York: Guilford Press.

Hodges, J., \& Oei, T. P. S. (2007). Would Confucius benefit from psychotherapy? The compatibility of cognitive behaviour therapy and Chinese values. Behaviour Research and Therapy, 45, 901-914.

Huang, K. G. (1987). Obligatory morality and utilitarian morality: Moral judgment and related issues in the Taiwanese society. In K. S. Yang \& H. Y. Chiu (Eds.), Taiwanese society in transition (p. 447-471). Taiwan: Nankang.

Hwang, W. C. (2006). The psychotherapy adaptation and modification framework. American Psychologist, 61 (7), 702-715.

Hwang, W., Wood, J. J., Lin, K., \& Cheung, F. (2006). Cognitive-behavioral therapy with Chinese Americans: Research, theory, and clinical practice. Cognitive and Behavioral Practice, 13(4), 293-303.

Kim, B. S., Atkinson, D. R. , \& Yang, P. H. (1999). The Asian values scale: Development, factor analysis, validation, and reliability. Journal of Counseling Psychology, 46 (3), 342 - 352.

Kim, B. S., Yang, P. H., Atkinson, D. R., Wolfe, M. M., \& Hong, S. (2001). Cultural value similarities and differences among Asian American ethnic groups. Cultural Diversity and Ethnic Monthly Psychology, 7 (4), 343-361.

Kim, U., Trandis, H. C., Katiticibasi, C., Choi, S. C., \& Yoon, G. (1994). Individualism and collectivism: Theory, method and application. Sage.

Koenig, T. L., \& Spano, R. N. (1998). Taoism and the strengths perspective. Social Thoughts, 18 (2), 47-65.

Lee, K. Xu, F., Fu, G., Cameron, C. A., \& Chen, S. (2001). Taiwan and Mainland Chinese and Canadian children's categorization and evaluation of lie- and truth-telling: A modesty effect. British Journal of Developmental Psychology, 19, 525-542.

Lewinsohn, P. M.., Munoz, R. F., Youngren, M. A., \& Zeiss, A. M. (1992). Control your depression, revised ed. New York: Fireside.

Lin, K. (2003). Negotiating Chinese values in America: A partial process of acculturation for Chinese immigrants. (Doctoral dissertation, Spalding University). University Microfilms International No. 3111024.

Lin, Y. N. (2001). The application of cognitive-behavioral therapy to counseling Chinese. American Journal of Psychotherapy, 55 (4), 46 - 58.

Louie, V. S. (2000). The role of immigrant family in second generation educational outcomes: The Chinese American case. (Doctoral dissertation, Yale University). University Microfilms International No. 9973724. 
Integrating Cognitive-Behavioral and Cognitive-Interpersonal Case Formulations:

A Case Study of a Chinese American Male

E.T. Liu

Pragmatic Case Studies in Psychotherapy, http://pcsp.libraries.rutgers.edu

Volume 3, Module 3, Article 1, pp. 1-33, 07-27-07 [copyright by author]

Master Venerable Hsing Yun (2006). Chung Mei Buddhist Temple [Online], http://www.houstonbuddhism.org/contentpage/NewsLetter/Chinese/2006/April/p1.htm (retrieved March 25, 2007).

Motto, J. A. (1989). Problems in suicide risk assessment. In D. G. Jacobs \& H. N. Brown (Eds.) Suicide: Understanding and responding: Harvard Medical School perspectives on suicide (pp. 129 - 142). Madison, CT: International Universities Press.

Padesky, C., \& Greenberger, D. (1995). Clinician's guide to mind over mood. New York: Guilford Press.

Persons, J. B. (1989). Cognitive therapy in practice: A case formulation approach. W. W. Norton \& Company, New York

Persons, J. B., Davidson, J., \& Tompkins, M. A. (2001). Essential components of cognitivebehavior therapy for depression. American Psychological Association, Washington DC

Persons, J. B. \& Tompkins, M. A. (1997). Cognitive-behavioral case formulation. In T.D. Eells, (Ed.), Handbook of psychotherapy case formulation, pp. 314-339. New York: Guilford Press.

Safran, J. \& Muran, J. (2000). Negotiating the therapeutic alliance: A relational treatment guide. New York: Guilford Press.

Safran, J. \& Segal, Z. (1990). Interpersonal Process in Cognitive Therapy. New York: Basic Books.

Stevenson, H. W., \& Lee, S. (1996). The academic achievement of Chinese students. In M. H. Bond (Ed.). The handbook of Chinese psychology (pp. 124-142). Hong Kong, Republic of China: Oxford University Press.

$\mathrm{Su}$, J. W. (1993). The deep structure of the Chinese culture. Hong Kong: Taishang.

Sue, D. W. (1997). Counseling strategies for Chinese Americans. In C. C. Lee (Ed.). Multicultural issues in counseling: New approaches to diversity. (pp. 173-187). American Association for Counseling and Development.

Sue, D. W. \& Sue, D. (2003). Counseling the culturally diverse: Theory and practice, $4^{\text {th }} \mathrm{ed}$. New York: Houghton Mifflin.

Tweed, R. G. \& Lehman, D. R. (2002).Learning considered within a cultural context: Confucian and Socratic approaches. American Psychologist, 57, 89-99.

Tompkins, M. A. (1996). Cognitive-behavioral case formulation, Journal of Psychotherapy Integration, 6 (2), $97-105$.

Tompkins, M. A. (1999). Using a case formulation to manage treatment nonresponse, Journal of Cognitive Psychotherapy: An International Quarterly, 13 (4), 317 - 330.

Walsh, R. (1989). Towards a synthesis of eastern and western psychologies. In A. Sheikh \& K. Sheikh (Eds.), Eastern and western approaches to healing: Ancient wisdom and modern knowledge (pp. 542-555). New York: John Wiley.

Yalom, I. D. (2002). The gift of therapy. HarperCollins Publishers.

Yang, K. S. (1986). Chinese personality and its change. In M. H. Bond (Ed.), Chinese psychology of the Chinese people (pp.106-170). Hong Kong: Oxford University press. 
Integrating Cognitive-Behavioral and Cognitive-Interpersonal Case Formulations:

A Case Study of a Chinese American Male

E.T. Liu

Pragmatic Case Studies in Psychotherapy, http://pcsp.libraries.rutgers.edu

Volume 3, Module 3, Article 1, pp. 1-33, 07-27-07 [copyright by author]

Table 1. TC's Anxiety and Depression Scores in the Beginning, Middle, and Final Phases of Therapy

\begin{tabular}{|l|c|c|}
\hline $\begin{array}{l}\text { Time of } \\
\text { Administration }\end{array}$ & $\begin{array}{l}\text { Burns Anxiety } \\
\text { Inventory } \\
\text { Score* }\end{array}$ & $\begin{array}{l}\text { Burns Depression } \\
\text { Inventory Score** }\end{array}$ \\
\hline $\begin{array}{l}\text { Beginning of } \\
\text { therapy }\end{array}$ & 30 & 31 \\
\hline $\begin{array}{l}\text { Middle of } \\
\text { therapy }\end{array}$ & 24 & 27 \\
\hline End of therapy & 16 & 15 \\
\hline
\end{tabular}

* $0-4$, minimal or no anxiety

$5-10$, borderline anxiety

11-20, mild anxiety

21-30, moderate anxiety

31-50, severe anxiety

51-99, extreme anxiety or panic (from Burns, 1989, p. 35)

** 0 - 4, minimal or no depression

5-10, borderline depression

11-20, mild depression

21-30, moderate depression

31-45, severe depression (from Burns, 1989, p. 37)

Table 2. TC's Sleep Ratings in the Beginning, Middle, and Final Phases of Therapy

\begin{tabular}{|l|c|}
\hline $\begin{array}{l}\text { Time of } \\
\text { Administration }\end{array}$ & Sleep Rating \\
\hline $\begin{array}{l}\text { Beginning of } \\
\text { therapy }\end{array}$ & $3^{*}$ \\
\hline Middle of therapy & 5 \\
\hline End of therapy & 7.5 \\
\hline
\end{tabular}

* The rating was made on the following scale: "On a scale of 0 to 10 , with 0 being very poor, and 10 being very good, how would you rate the quality of your sleep in the past week?" 
Integrating Cognitive-Behavioral and Cognitive-Interpersonal Case Formulations:

A Case Study of a Chinese American Male

E.T. Liu

Pragmatic Case Studies in Psychotherapy, http://pcsp.libraries.rutgers.edu

Volume 3, Module 3, Article 1, pp. 1-33, 07-27-07 [copyright by author]

Table 3. TC's School Grades in the Beginning, Middle, and Final Phases of Therapy

\begin{tabular}{|l|c|}
\hline Time & School Grades \\
\hline Prior to Therapy & 2B's \& 2C's \\
\hline $\begin{array}{l}\text { First Semester } \\
\text { (During Therapy) }\end{array}$ & 3B's \\
\hline $\begin{array}{l}\text { Second Semester } \\
\text { (During Therapy) }\end{array}$ & 3A's \& 1B \\
\hline
\end{tabular}

